\title{
Design of a Lunar Solar Wind Volatiles Extraction System
}

\author{
Aaron D.S. Olson, John F. Santarius, Gerald L. Kulcinski
}

\begin{abstract}
Engineering Physics Department, University of Wisconsin-Madison, Madison, WI
\end{abstract}
Two devices are being developed as part of a project to demonstrate the extraction of helium-3 and other volatiles from lunar regolith. The first is an implantation system to embed helium ions into JSC-1A lunar regolith simulant and the second is a counter flow heat pipe heat exchanger for the subsequent diffusion of the helium out of the regolith. This will simulate the previously proposed acquisition of helium-3 from the Moon for use in nuclear fusion reactors on Earth. Preliminary designs of both of these systems are discussed. ${ }^{1}$

\section{Introduction}

Of the various volatile materials available on the Moon, there is potentially only one that has significant value back on Earth. Helium-3 $\left({ }^{3} \mathrm{He}\right)$, if used as fuel in a nuclear fusion reactor, could become a significant lunar export for power generation around the world. The nuclear fusion reactions using ${ }^{3} \mathrm{He}$ :

$$
\begin{aligned}
& \mathrm{D}+{ }^{3} \mathrm{He} \rightarrow \mathrm{p}(14.68 \mathrm{MeV})+{ }^{4} \mathrm{He}(3.67 \mathrm{MeV}) \\
& { }^{3} \mathrm{He}+{ }^{3} \mathrm{He} \rightarrow 2 \mathrm{p}+{ }^{4} \mathrm{He} \quad(12.86 \mathrm{MeV})
\end{aligned}
$$

are promising for commercial future fusion reactors due to their high energy output and their low emission of neutrons, higher energy conversion efficiency, increased safety and potential ease of maintenance compared to the more studied deuterium-tritium (DT) fuel cycle. Unfortunately, there is not enough terrestrial ${ }^{3} \mathrm{He}$ to support its use for power generation. ${ }^{1}$ It was realized in 1985 that there is $\sim 10^{6}$ tonnes of ${ }^{3} \mathrm{He}$ embedded in the lunar regolith from over 4 billion years of the Moon being bombarded by the solar wind. The seminal article tying lunar ${ }^{3} \mathrm{He}$ to fusion development was published by researchers at the University of Wisconsin-Madison's Fusion Technology Institute (FTI) in 1986. ${ }^{2}$ Three designs of lunar ${ }^{3} \mathrm{He}$ miners have been developed at the FTI: the Mark-I, II, and III (M-1 through M-3). ${ }^{3-5}$ The

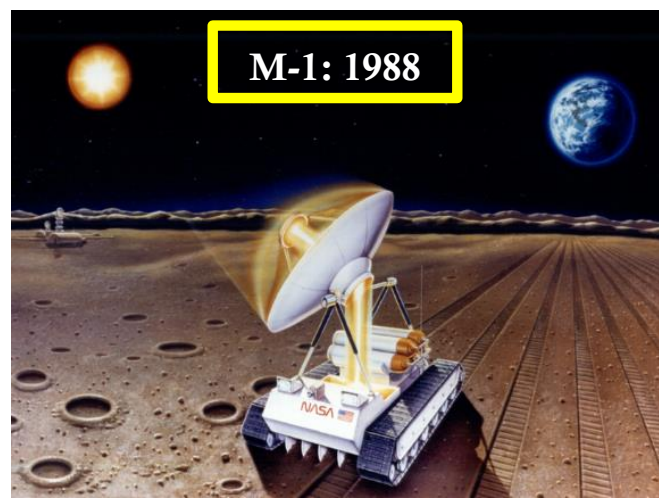

Figure 1. Illustration of the Mark I helium-3 lunar volatiles miner $^{3}$ (Credit: John Andrews)

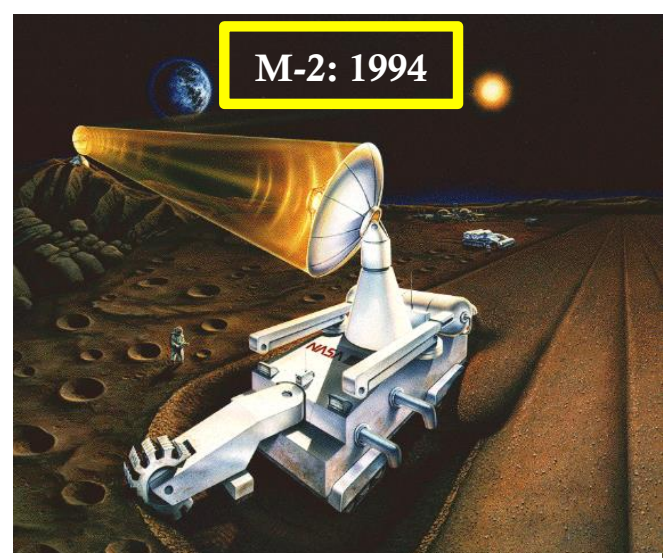

Figure 2. Illustration of the Mark II helium-3 lunar volatiles miner $^{4}$ (Credit: I. Sviatoslavsky)

The Wisconsin Space Grant Consortium (WSGC) graciously provided funding in support of the work presented in this paper. The Greatbach Foundation and Grainger Foundation were also instrumental in support of this work. 
most recent of these designs was completed in 2006. The M-3 miner was designed to return $33 \mathrm{~kg}$ of ${ }^{3} \mathrm{He}$ to Earth each year after excavating to $3 \mathrm{~m}$ depth over a $1 \mathrm{~km}^{2}$ area. This would be enough to fuel one $\sim 400 \mathrm{MWe}$ fusion power plant. The $33 \mathrm{~kg} / \mathrm{yr}$ collection rate assumes a $10 \mathrm{ppb}{ }^{3} \mathrm{He}$ grade (by mass) and that the miner only operates during $90 \%$ of the lunar daytime (3942 hours/year). It is thought that the ${ }^{3} \mathrm{He}$ grade in the undisturbed maria regolith should actually be closer to $20 \mathrm{ppb}^{6}$ and with this in mind, the collection would be closer to $66 \mathrm{~kg} / \mathrm{yr}$. The other solar wind volatiles $\left(\mathrm{H}_{2},{ }^{4} \mathrm{He}, \mathrm{CO}_{2}, \mathrm{CH}_{4}, \mathrm{~N}_{2}, \mathrm{H}_{2} \mathrm{O}\right)$, which diffuse out of the regolith with heating, could also be collected for the life support needs of astronauts anywhere in cislunar space or beyond (water, oxygen, atmosphere, food growth) and/or fuel for spacecraft. These other volatiles are present in the lunar regolith in much higher concentrations than ${ }^{3} \mathrm{He}$ as seen in Table 1 , and in a mining operation where each miner collects $66 \mathrm{~kg} / \mathrm{yr}$ of ${ }^{3} \mathrm{He}$, these volatiles could be collected to support hundreds of people in space. ${ }^{7}$ The M-3 miner design employs a continuous volatile extraction process where regolith is excavated with a bucket wheel excavator before entering the internal processing portions of the miner. Inside the miner, regolith is beneficiated in a series of sieves, screw conveyors and a fluidized bed so that only particles larger than 100 microns are rejected. Particles smaller than 100 microns enter a heating system where the volatiles are evolved by diffusion out of the regolith.

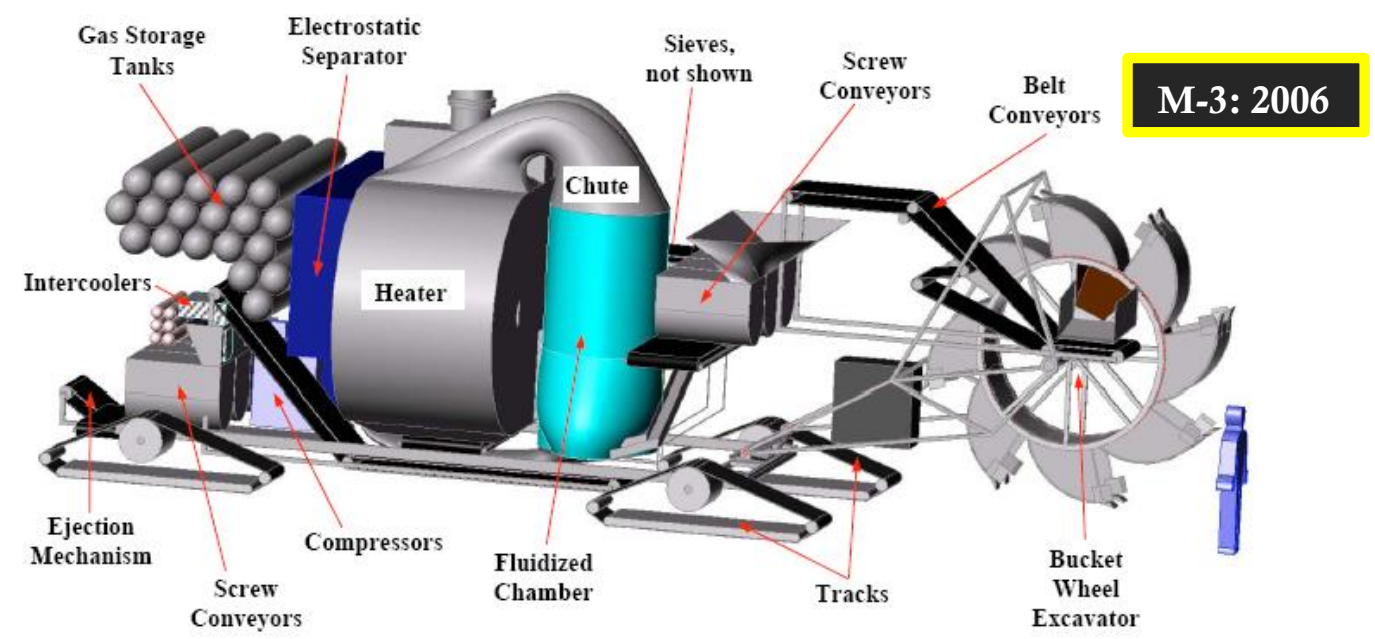

Figure 3. Model of the interior components of the Mark III helium-3 lunar volatiles miner ${ }^{5}$ (Credit: M. Gajda) 
Table 1. Volatiles Products of Heating Mare Regolith to $700{ }^{\circ} \mathrm{C}$

\begin{tabular}{|c|c|c|c|}
\hline Volatile & $\begin{array}{c}\text { Mass } \\
\text { evolved } \\
\text { per tonne } \\
\text { of regolith } \\
\text { mined (g)* }\end{array}$ & $\begin{array}{c}\text { Mass } \\
\text { evolved } \\
\text { per kg of } \\
\mathbf{3} \text { He } \\
\text { evolved } \\
\text { (kg) }\end{array}$ & $\begin{array}{c}\text { Mass } \\
\text { extracted } \\
\text { (tonnes/yr) } \\
* *\end{array}$ \\
\hline $\mathrm{H}_{2}$ & 43 & 6100 & 201 \\
\hline${ }^{4} \mathrm{He}$ & 22 & 3100 & 102 \\
\hline${ }^{3} \mathrm{He}$ & 0.007 & 1 & 0.066 \\
\hline $\mathrm{H}_{2} \mathrm{O}$ & 23 & 3300 & 109 \\
\hline $\mathrm{N}_{2}$ & 4.0 & 500 & 16.5 \\
\hline $\mathrm{CH}_{4}$ & 11 & 1600 & 53 \\
\hline $\mathrm{CO}^{3}$ & 13.5 & 1900 & 63 \\
\hline $\mathrm{CO}_{2}$ & 12 & 1700 & 56 \\
\hline$*$ After beneficiation, $450 \mathrm{~kg}$ of regolith is heated \\
\hline$* *$ With 20 ppb and 1258 tonnes/hr excavation \\
\hline
\end{tabular}

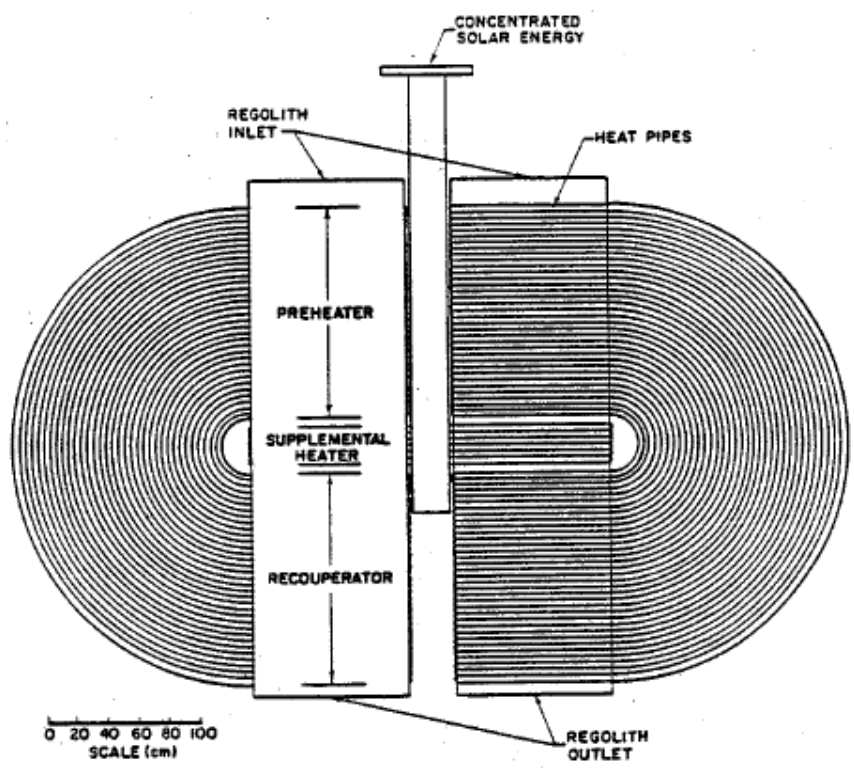

Figure 4. Illustration of the heat pipe heat exchanger designed for the Mark series of helium-3 lunar volatiles miners. ${ }^{3}$ The system is scaled to heat $157 \mathrm{~kg} / \mathrm{s}$ of regolith from $30{ }^{\circ} \mathrm{C}$ up to $700{ }^{\circ} \mathrm{C}$.

The heating system is effectively a counter flow heat pipe heat exchanger that consists of preheater, supplemental heater, and recuperator sections of heat pipes. Concentrated solar energy is transferred to the supplemental section of heat pipes from a solar collector. The heating system brings the temperature of the $<100$ micron regolith particles up to $700{ }^{\circ} \mathrm{C}$ from an inlet temperature of $30^{\circ} \mathrm{C}$ to evolve the embedded volatiles while also recuperating heat from the waste regolith, in the recuperator section, before it exits the heating system. Using Apollo 11 sample 10086.16, it was shown that heating maria regolith from Mare Tranquillitatis up to $700{ }^{\circ} \mathrm{C}$ releases $85 \%$ of the trapped ${ }^{3} \mathrm{He}^{8}{ }^{\text {To produce }} 33 \mathrm{~kg} / \mathrm{yr}$ of ${ }^{3} \mathrm{He}$ (assuming $10 \mathrm{ppb}$ ) at an energy recovery efficiency of $85 \%, 12.3 \mathrm{MWt}$ is required from the solar collector for a $157.3 \mathrm{~kg} / \mathrm{s}$ mass flow rate of processed regolith. A total of $21,5001.5 \mathrm{~cm}$ diameter heat pipes, with their $1 \mathrm{~m}$ long condenser sections acting as the preheater and their $1 \mathrm{~m}$ long evaporator sections acting as the recuperator, would be required. The working fluid in the heat pipes varies with depth in the heating system from water in the lowest temperature rows of heat pipes (near the inlet) progressing to mercury, potassium and eventually sodium next to and in the supplemental heater section. The pressure inside of the heating system was chosen to be $20 \mathrm{kPa}$. The gas in the heating system is the released volatile gas mixture, which is mostly $\mathrm{H}_{2}$ and ${ }^{4} \mathrm{He}$. Figure 4 illustrates the concept of the heat pipe heat exchanger for the Mark series of ${ }^{3} \mathrm{He}$ and lunar volatiles miners. The heating system is approximately $5 \mathrm{~m}$ in length, $2 \mathrm{~m}$ in width and $3 \mathrm{~m}$ in height. It is estimated to be $\sim 9$ tonnes. Figure 5 shows the model of the heat exchanger where the 21,500 heat pipes that make up the heating system are shown at three different viewing scales. 


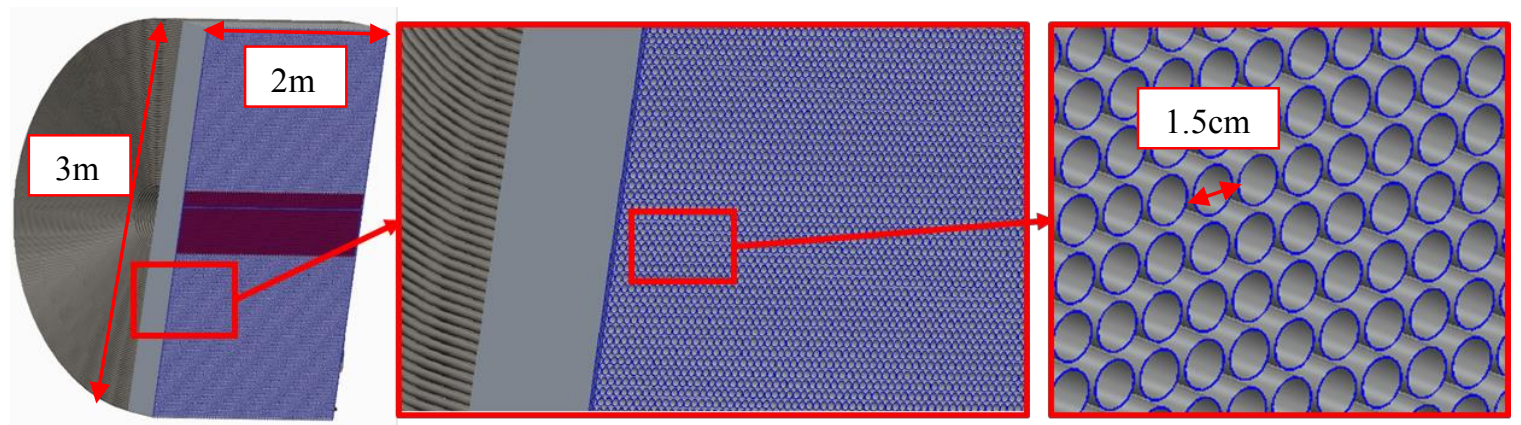

Figure 5. Model of the Mark series miners' heating system on three different viewing scales, demonstrating the size of the system relative to an individual heat in the system.

\section{Small Scale Heat Pipe Heat Exchanger}

Currently at the FTI, work is being done to demonstrate the process of acquiring ${ }^{3} \mathrm{He}$ from lunar regolith on a small scale, which could lead to eventual large scale acquisition for future nuclear fusion reactors. The extraction technique described above is the design baseline for the demonstration system. In lieu of a solar concentrating system to provide heating power to the heating system, electrical resistance heating (Joule heating) will be used for simplicity. A 1:1000 scale

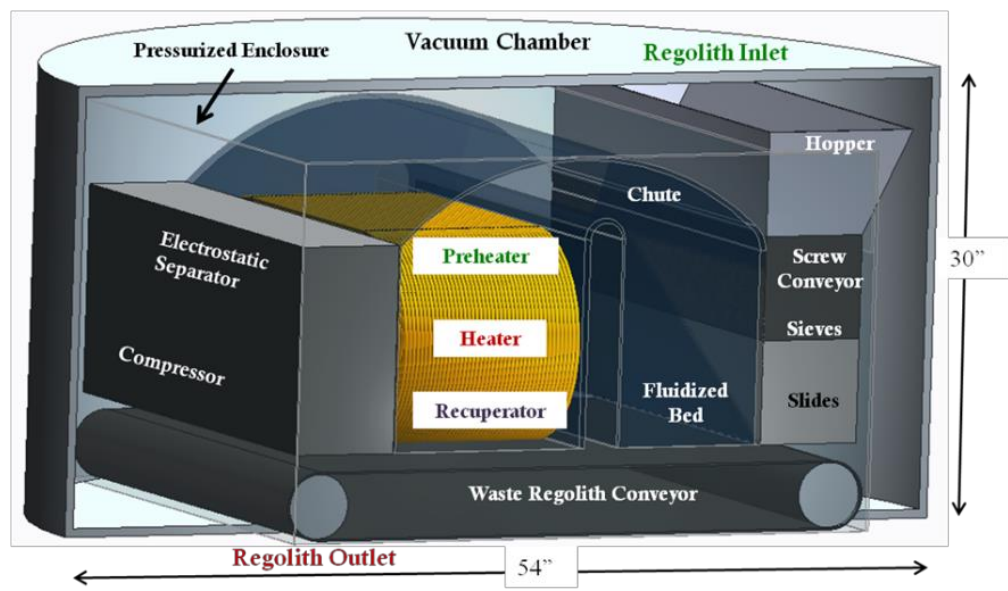

Figure 6. Concept of a demonstration lunar volatiles extraction systm with a heat pipe heat exchanger heating system compared to the M-3 was selected for an initial demonstration system. This means that the demonstration unit will need to heat a regolith mass flow rate $(\dot{m})$ of $0.157 \mathrm{~kg} / \mathrm{s}$. With this mass flow rate known, the heating system design comes down to determining the required heat transfer area for a given heat exchanger configuration. The aforementioned heating system configuration is a counter flow heat exchanger with a capacity ratio of unity because the regolith going through the preheater has the same specific heat as the regolith going through the recuperator. The number of thermal transfer units $(N T U)$ for a heat exchanger such as this can be determined as a function of effectiveness $(\varepsilon)$ using the standard formula shown in Eq. (1) below. ${ }^{9}$ Effectiveness is the ratio of heat transfer in the heat exchanger to the maximum possible heat transfer while NTU is a heat exchanger's total thermal conductance $(U A)$ over its capacitance rate, $\dot{C}$, as seen in Eq. (2). Total thermal conductance is the inverse of total thermal resistance $\left(R_{t o t}\right)$ and the capacitance rate is simply the product of the mass flow rate and the specific heat $\left(C_{p}\right)$ of the regolith.

$$
N T U=\frac{\varepsilon}{1-\varepsilon}
$$




$$
N T U=\frac{U A}{\dot{C}}
$$

In this case the effectiveness is the same as the prescribed energy recovery efficiency, and thus the heat exchanger's total conductance can be directly determined with Eq. (1) and Eq. (2). The effectiveness of $85 \%$ was kept from the full scale M-3 design, but could be varied in future demonstrations. Heat pipe effective thermal conductivities can be 3 to 4 orders of magnitude larger than the best solid conductors (e.g., copper). ${ }^{10}$ With this in mind, the thermal resistance of the heat pipes has been neglected in the calculation of total thermal resistance. The only resistance taken into account is that due to convection heat transfer at the condenser (preheater section) and the evaporator (recuperator section) surfaces of the heat pipes. The condenser and evaporator surface areas $\left(A_{\text {pre }}\right.$ and $\left.A_{\text {rec }}\right)$ have to be equal for the heat exchanger to operate as intended, and thus the total thermal resistance can be described as shown in Eq. (3). The heat transfer coefficient $(h)$ can be determined from an appropriate Nusselt number $(\mathrm{Nu})$ correlation. For this configuration the Dittus-Boelter correlation was used as seen in Eq.(4) with the Reynolds number $(R e)$ and Prandtl number $(P r)$ defined as in Eqs. (5). The hydraulic diameter $\left(D_{h}\right)$ for the flow paths in the heat pipe arrangement was calculated as shown in Eqs. (5) with the distance between outer walls of consecutive columns of heat pipes $(\delta)$ and the evaporator section length of a heat pipe $\left(L_{\text {pipe }}\right)$. The regolith bulk density $(\rho)$ used is $1700 \mathrm{~kg} / \mathrm{m}^{3}$, and the specific heat of the regolith used is 800 $\mathrm{J} /(\mathrm{kgK})$. The thermal conductivity $(K)$ of the bulk regolith was taken to be $0.4 \mathrm{~W} /(\mathrm{mK})$ by augmenting thermal conductivity values measured for JSC-1A simulant at $25 \mathrm{kPa}$ in air. ${ }^{11}$ In a $\mathrm{H}_{2}$ and ${ }^{4} \mathrm{He}$ environment at $20 \mathrm{kPa}$, the bulk regolith thermal conductivity should increase like Deissler and Boegli showed for similar granular materials. ${ }^{12}$ The viscosity of the flowing regolith was taken to be $2.1 \times 10^{-4}$ (Pa s) as Sviatoslavsky used. ${ }^{3}$

$$
\begin{gathered}
(U A)^{-1}=R_{\text {tot }}=\left(\frac{1}{h A_{\text {pre }}}\right)+\left(\frac{1}{h A_{\text {rec }}}\right)=\frac{2}{h A} \\
N u=0.023 R e^{4 / 5} \mathrm{Pr}^{2 / 5}=\frac{h D_{h}}{K} \\
\operatorname{Re}=\frac{\rho U_{\text {avg }} D_{h}}{\mu} \quad \operatorname{Pr}=\frac{C_{p} \mu}{K} \quad D_{h}=\frac{2 \delta L_{\text {pipe }}}{\delta+L_{\text {pipe }}}
\end{gathered}
$$

The calculation of the Reynolds number requires the average velocity $\left(U_{\text {avg }}\right)$ of the bulk regolith through the heat pipe matrix. A capillary model, for flow through paths in a porous medium, was used to model the flow between the heat pipes and estimate the average regolith velocity for a given average flow area $\left(A_{\text {avg }}\right)$ and effective gravitational pressure drop $\left(\frac{d P}{d z}\right)$ as shown in Eqs. (6). ${ }^{13}$ The effective gravitational pressure drop was simply taken as the product of the height that the regolith falls from the heating system inlet to the supplemental heater section $\left(H_{\text {pre }}\right)$, with the gravitational acceleration on Earth $(g)$ and the density of the bulk regolith simulant over the effective flow path length $\left(L_{e f f}\right)$ through the preheater section of the pipe matrix. 


$$
\dot{m}=\rho U_{\text {avg }} A_{\text {avg }}=\frac{\pi \rho D_{h}^{4}}{128 \mu}\left(\frac{d P}{d z}\right) \quad\left(\frac{d P}{d z}\right)=\frac{\rho g H_{\text {pre }}}{L_{\text {eff }}}
$$

The counter flow heat exchanger and capillary flow model relations presented above allow for the solution of a heat pipe arrangement given appropriate bounds on the system's overall height $(H)$, heat pipe diameter $(D)$ and condenser/evaporator section length $\left(L_{\text {pipe }}\right)$. An optimum (massminimized) configuration was determined in which the number of heat pipe columns $\left(N_{c o l}\right)$ and rows $\left(N_{\text {row }}\right)$ were determined as well as the inter-pipe distance across a row. The number of columns was rounded up to 7, the number of rows was rounded up to 17, and $\delta$ was found to be $\sim 1 \mathrm{~mm}$. For simplicity, the supplemental heater section uses heating rods of the same diameter as the heat pipes. Assuming that all of the heating rods' external surface area is at the same temperature $\left(T_{S}\right)$ of $800{ }^{\circ} \mathrm{C}$, the number of required electrical resistance heating rods can be determined by dividing the total length that the regolith needs to flow between the heating rods $\left(H_{\text {supp }}\right)$ to reach its peak temperature of $700{ }^{\circ} \mathrm{C}$ by the pipe diameter. The length is calculated using an internal pipe flow model with the same hydraulic diameter presented above as shown in Eqs. (7). ${ }^{14}$ The perimeter ( $p e r$ ) of the flow path between the heating rods is the product of twice the number of heat pipe columns and the sum of the heat pipe evaporator section length and inter heat pipe distance, also shown in Eqs. (7). The result was rounded up to 2 rows of electrical heating rods.

$$
T_{\text {outlet }}=\left(T_{\text {inlet }}-T_{S}\right) \exp ^{\left(\frac{-(\text { per }) \mathrm{hH}_{\text {supp }}}{\dot{C}}\right)}+T_{S} \quad \text { per }=2 N_{\text {col }}\left(L_{\text {pipe }}+\delta\right)
$$

The entire heating system mass is $5.4 \mathrm{~kg}$ (excluding the heat pipe working fluid) with heat pipes of stainless steel wall material, $1.5 \mathrm{~cm}$ diameter and $0.25 \mathrm{~mm}$ thickness and solid stainless steel heater rods also with $1.5 \mathrm{~cm}$ diameter. The heat pipe and heating rod configuration is shown on the left of Figure 7. A CFD model of the bulk regolith flow and heat transfer through the heat pipe matrix was created to compare to the analytical results. The model takes into account the tortuisity of the flow path, the varying effective flow channels between the heat pipes, and a varying heat transfer coefficient through the pipe matrix as well. A velocity magnitude contour plot resulting from the CFD model is shown in the center of Figure 7. A temperature contour plot of the regolith through the heat pipe matrix is shown on the right in Figure 7. The velocity results of the CFD model match that of the capillary model in the vertical flow paths through the pipe matrix within $10 \%$. The CFD model's thermal results confirm that regolith will reach a maximum temperature of $700^{\circ} \mathrm{C}$ and therefore release the anticipated amount of implanted volatiles. 

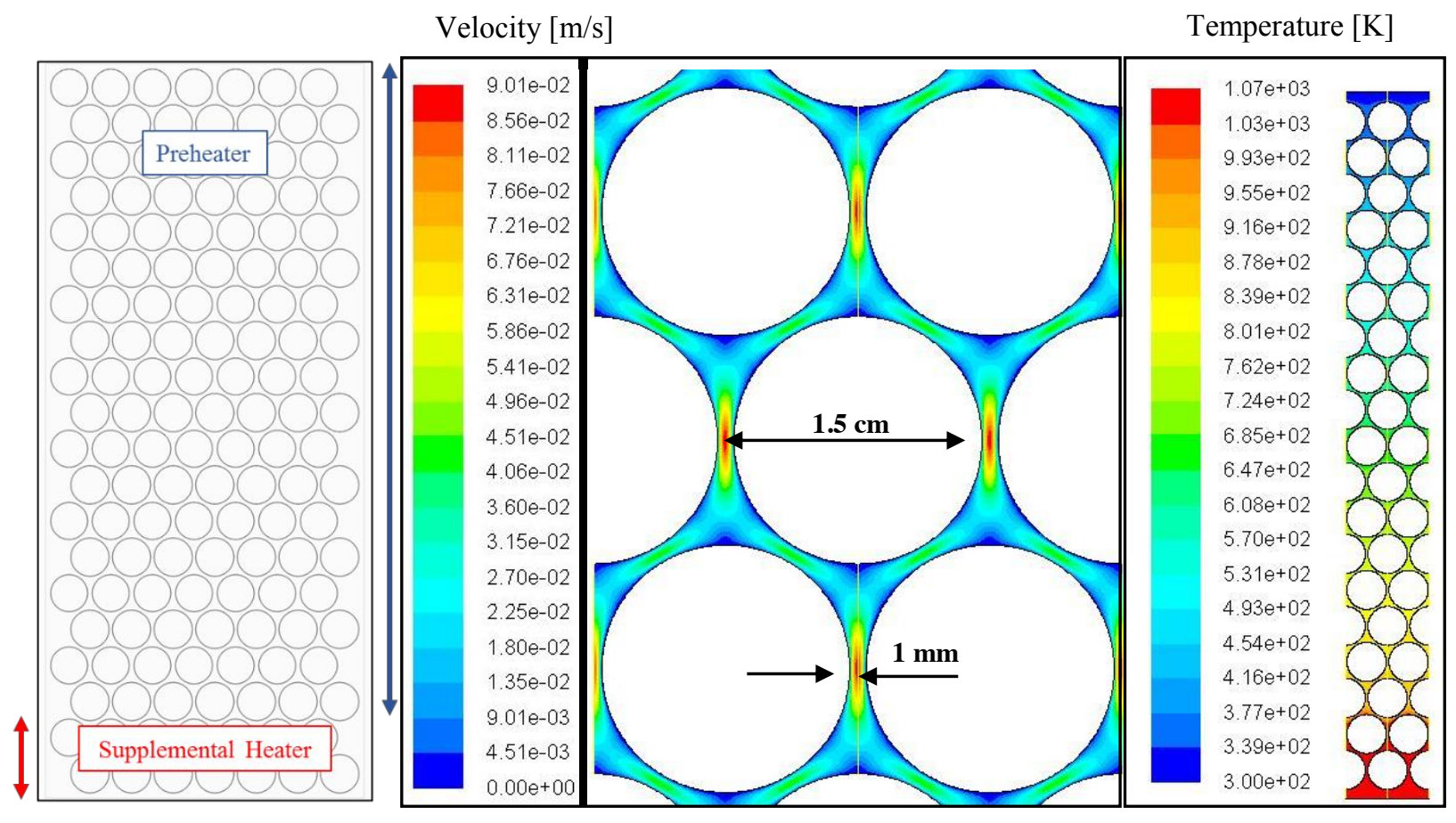

Figure 7. Heat pipe arrangement in the preheater and supplemental heat exchanger sections (left), contour plot of bulk regolith velocity through the heat pipe matrix (center) and a contour plot of the temperature variation of the regolith with depth through the scale heat pipe heat exchanger (right).

Modifications to the CFD model will allow for particle tracking, where the percentage of particles actually reaching the maximum temperature can be determined, and more accurate results that take into account the cohesiveness that may develop amongst the regolith particles as they flow through the heating system. There is a significant amount of work remaining before this demonstration heating system can be constructed and tested. Beyond the model modifications described above, in depth analysis on the individual rows of heat pipes will need to be completed. In the foregoing heat exchanger analysis it was assumed that all of the heat pipes provide the same amount of heat to the regolith. This will almost certainly not be the case due to the differences in the operational characteristics of heat pipes with different working fluids. A revised design will take this into account along with the transient behavior of the heating system, so that an estimate for the startup time and energy can be determined as a function of the overall system's energy recovery efficiency. The movement of the regolith prior to the heat exchanger inlet and after the heat exchanger outlet will also need to be taken into consideration. The instrumentation of the demonstration unit must also be developed. It is envisioned that a residual gas analyzer will be used to monitor the evolution of volatiles out of the regolith while thermocouples probes will gather temperature measurements at various locations inside of the heat exchanger.

\section{Implantation of Helium into Regolith Simulant}

Before demonstrating the evolution of ${ }^{3} \mathrm{He}$ out of regolith simulant, simulant that is embedded to a known concentration must be available in order to gauge the performance of the extraction system. Beyond the Apollo and Lunakhod lunar soil samples, there is no regolith or regolith simulant that has already been implanted with solar wind volatiles that is available for 
experimental studies. An implantation device is being developed to implant helium-4 into batches of JSC-1A simulant. Helium-3 will only be used after the device's operational performance is completely tested in order to keep costs down. Of the numerous known implantation techniques, implantation by a dc plasma discharge was chosen for this implantation device because of its relative simplicity. In a dc glow discharge an electrical potential, or voltage, is held between two parallel electrodes (plates) under a controlled pressure environment. Empirical results have given curves of the required breakdown voltage $\left(V_{b}\right)$ to start the glow discharge as a function of the product of pressure and distance between the electrodes for a given gas. ${ }^{15}$ These curves are referred to as Paschen curves. For helium ions to implant in regolith simulant with approximately the same average energy as the helium ions do on the lunar surface $^{2}$, an $\sim 8 \mathrm{kV}$ potential is required. Using this as the breakdown voltage, a pressure-distance

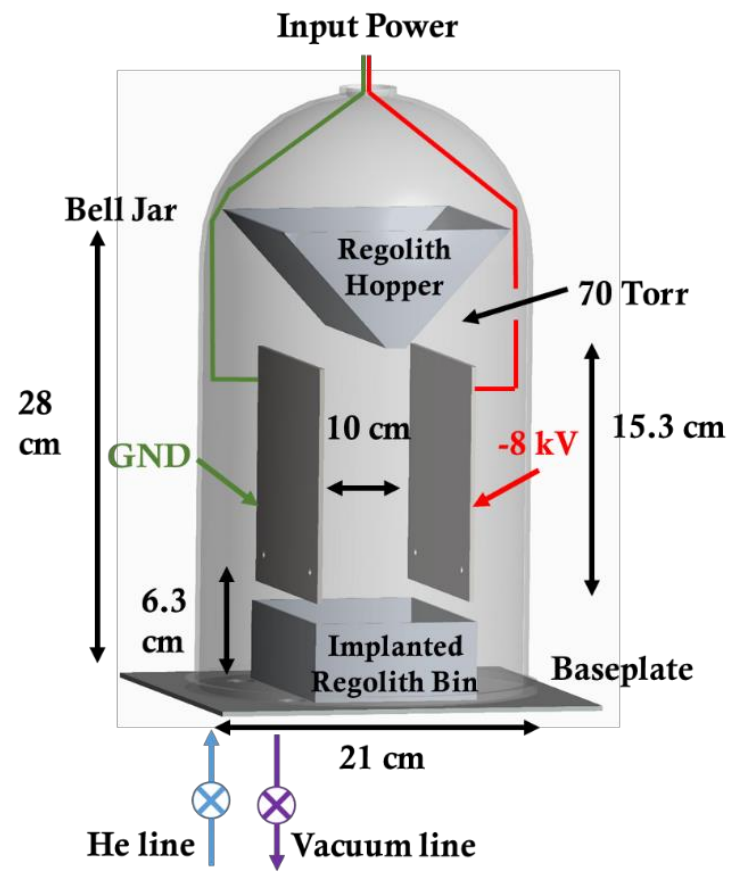

Figure 8. Concept of a de plasma discharge implantion device for lunar regolith simulant product $(P d)$ can be determined from Eqs. (8). It should be noted that Paschen curves are nonlinear and that there are actually two different pressuredistance products that could initiate the glow discharge at an $8 \mathrm{kV}$ breakdown voltage. To avoid the additional cost of using a high vacuum system for the implantation device, the larger pressuredistance product of $933 \mathrm{~Pa}-\mathrm{m}$ was selected. The preliminary design utilizes an available borosilicate glass bell jar as the vacuum chamber. The chamber is $21 \mathrm{~cm}$ in inner diameter and 28 $\mathrm{cm}$ in cylindrical height with a hemispherical dome. The size restrictions of the bell jar led to a plate spacing of $10 \mathrm{~cm}$, which in turn determined a pressure of $9.33 \mathrm{kPa}$ (70 Torr) for the helium inside of the chamber. The concept of the implantation device is that regolith will be implanted when it flows out of a wedge shaped hopper and between the electrodes as shown in Figure 8.

$$
A^{\prime} P d \exp \left(-\frac{B^{\prime} P d}{V_{b}}\right)=\ln \left(1+\left(\frac{1}{\gamma_{s e}}\right)\right) \quad A^{\prime}=2.1 P a^{-1} m^{-1} \quad B^{\prime}=57.75 \frac{V}{P a-m} \quad \gamma_{s e}=0 .
$$

It is important to consider the electron collision probability with the regolith simulant between the electrodes. If the probability of collision $\left(P_{\text {coll }}\right)$ is too high, the discharge will not sustain itself. This will occur if the flow of regolith between the electrodes is too dense. Porosity in the regolith flow between the electrodes plates can be achieved by introducing a sieve at the hopper's outlet orifice and through the use of a gate mechanism that slides under the orifice to limit flow. With an appropriate number density of regolith particles $(n)$ between the plates at any given time, the mean free path $(\lambda)$ of electrons through the regolith particles will be sufficiently large to keep the electron collision probability $\leq 0.5$, which should keep the discharge going. The relationship between the mean free path and collision probability is shown in Eq. (9) where the cross section 
of the regolith particles $(\sigma)$ is set by the average diameter $\left(D_{p}\right)$ of the JSC-1A simulant, $\sim 100$ microns.

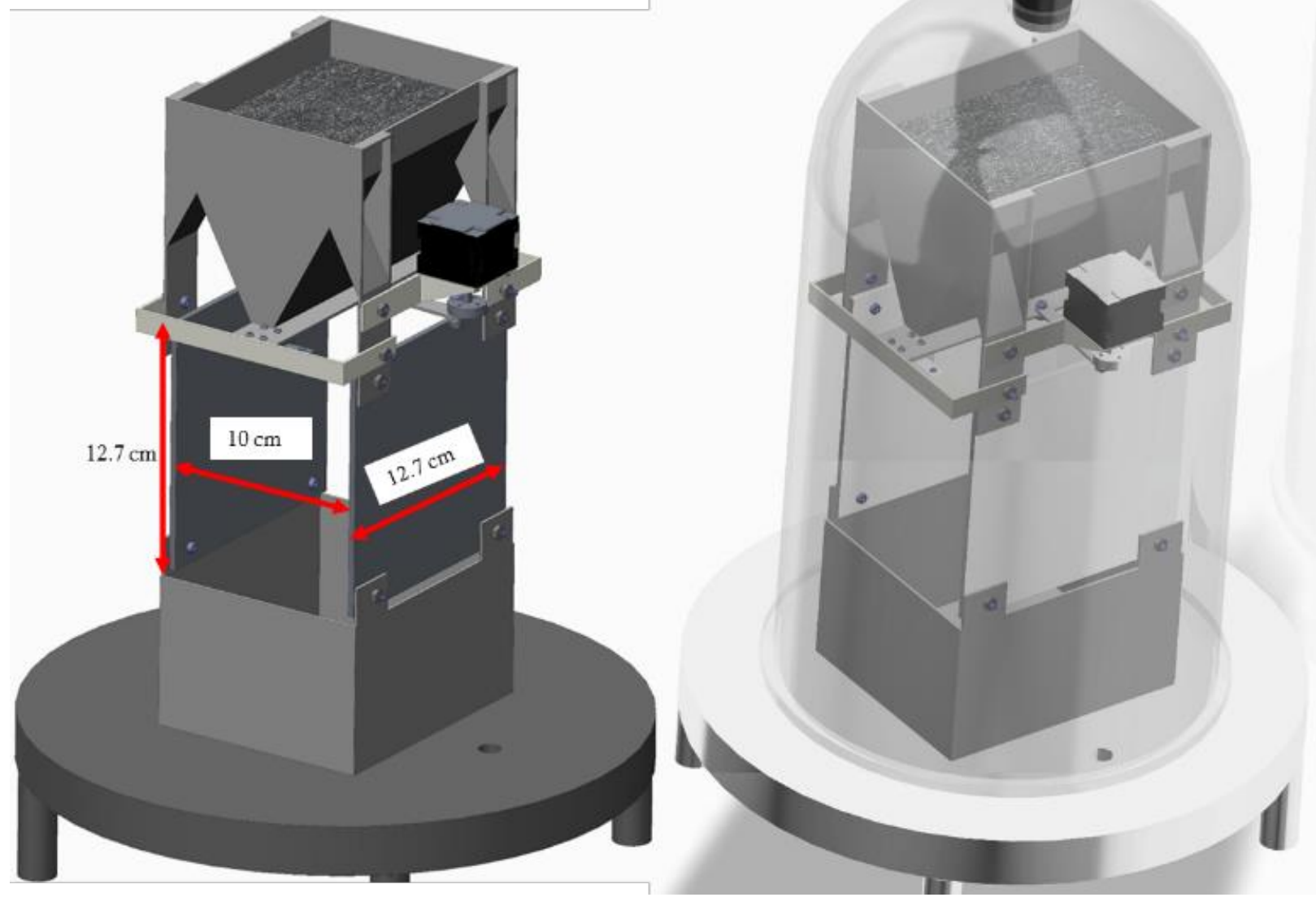

Figure 9. Preliminary design of a dc glow discharge implantation system for regolith simulant

$$
P_{\text {coll }}=1-\exp \left(-\frac{x}{\lambda}\right) \quad \lambda=(n \sigma)^{-1} \quad \sigma=\pi D_{p}^{2}
$$

One configuration that could allow the discharge to persist, and therefore the implantation of helium into the JSC-1A simulant to occur, is shown in Fig. 9. This configuration uses a stepper motor to control a gate mechanism of the hopper and has a \#140 size standard sieve mesh that allows particles $<106$ microns to pass and blocks out $65 \%$ of the cover hopper orifice.

\section{Conclusion}

A significant amount of progress has been made toward the goal of demonstrating the process of extracting ${ }^{3} \mathrm{He}$ from lunar regolith in a manner that could eventually support future nuclear fusion reactors. The general parameters of the aforementioned heat pipe heat exchanger have been established such as the heat pipe arrangement and geometry. CFD simulation of the flow through the heat pipe matrix shows that the regolith will indeed reach the required temperature to release $85 \%$ of the embedded ${ }^{3} \mathrm{He}$. The preliminary design of the implantation system has been developed. 
The parameters of the de glow discharge that will implant helium into the regolith have been chosen and the supporting structural and vacuum elements of the system were discussed. Attention has been paid to the electron collision probability, which will determine whether the discharge continues when regolith is falling between the electrode plates of the discharge.

\section{References}

1 Wittenberg, L. J., "Terrestrial Sources of Helium-3 Fusion Fuel- A Trip to the Center of the Earth," Fusion Technology, vol. 15, 1989.

2 Wittenberg, L. J., Santarius, J. F., and Kulcinski, G. L., "Lunar Source of He-3 for Commercial Fusion Power," Fusion Technology, vol. 10, 1986, p. 167.

3 Sviatoslavsky, I. N., and Jacobs, M. K., "Mobile Helium-3 Mining and Extraction System and Its Benifits Toward Lunar Base Self-Sifficiency," Wisconsin Center for Space Automation and Robotics Technical Report (WCSAR-TR) AR3-8808-1, 1988.

$4 \quad$ Sviatoslavsky, I. N., "The Challenge of Mining He-3 on the Lunar Surface: How All the Parts Fit Together," Space 94, The 4th International Conference and Exposition on Engineering, Construction and Operations in Space, and The Conference and Exposition/Demonstration on Robotics for Challenging Environments, February 26 March 3, 1994, Albuquerque NM Also: WCS, 1993.

5 Gajda, M., "A Lunar Volatiles Miner," University of Wisconsin-Madison, M.S. Thesis, 2006.

6 Schmitt, H. H., "Return to the Moon," Return to the Moon, Praxis, 2005, p. 89.

7 Olson, A. D. S., "The Mark IV: A Scalable Lunar Miner Prototype," International Astronautical Congress 2013, Beijing, China, IAC-13.A3.2B.7, 2013.

8 Gibson Jr., E. R., and Johnson, S. M., "Thermal Analysis-Inorganic Gas Release Studies of Lunar Samples," 2nd Lunar Science Conference Vol. 2, 1971, pp. 1351-1366.

$9 \quad$ Nellis, G., and Klein, S., "Heat Exchangers," Heat Transfer, 2009, p. 857.

10 Thermacore, "Heat pipe and thermal management solutions, Thermacore," Thermacore.com Available: http://www.thermacore.com/thermal-basics/heat-pipetechnology.aspx.

11 Yuan, Z. G., and Kleinhenz, J. E., "Gas Phase Pressure Effects on the Apparent Thermal Conductivity of JSC-1A Lunar Regolith Simulant," 41 st International Conference on Environmental Systems, 2011, pp. 1750-1757.

12 Deissler, R. G., and Boegli, J. S., "An Investigation of Effective Thermal Conductivities of Powders in Various Gases," Transactions of American Society of Mechanical Engineers, vol. 81, 1958, pp. 1417-1425.

13 Fan, L. S., and Zhu, C., "Ch.5. Basic Equations," Principles of Gas Solid Flow, 1997, p. 224.

14 Nellis, G., and Klein, S., "Ch. 5. Internal Forced Convection," Heat Transfer, 2009, p. 686.

15 Lieberman, M. A., and Lichtenberg, A. J., "Ch. 14. Direct Current (DC) Discharges," Principles of Plasma Discharges and Materials Processing, 2005, p. 545. 